\title{
Label-Free Proteomic Analysis of Molecular Effects of 2-Methoxy-1,4-naphthoquinone on Penicillium italicum
}

\author{
Meixia Guo ${ }^{1}$, Xiaoyong Zhang ${ }^{2}$, Meiying $\mathrm{Li}^{1}$, Taotao $\mathrm{Li}^{3}{ }^{3}$, Xuewu Duan ${ }^{3}$, Dandan Zhang ${ }^{3}$, \\ Lianmei $\mathrm{Hu}^{4, *}$ and Riming Huang ${ }^{1, *}$ \\ 1 Guangdong Provincial Key Laboratory of Food Quality and Safety, College of Food Science, \\ South China Agricultural University, Guangzhou 510642, China \\ 2 Joint Laboratory of Guangdong Province and Hong Kong Region on Marine Bioresource Conservation and \\ Exploitation, College of Marine Sciences, South China Agricultural University, Guangzhou 510642, China \\ 3 Guangdong Provincial Key Laboratory of Applied Botany, South China Botanical Garden, \\ Chinese Academy of Sciences, Guangzhou 510650, China \\ 4 College of Veterinary Medicine, South China Agricultural University, Guangzhou 510642, China \\ * Correspondence: hulianmei@scau.edu.cn (L.H.); huangriming@scau.edu.cn (R.H.); \\ Tel.: +86-20-875-71321 (L.H.); +86-20-852-83448 (R.H.)
}

Received: 22 May 2019; Accepted: 10 July 2019; Published: 14 July 2019

\begin{abstract}
Penicillium italicum is the principal pathogen causing blue mold of citrus. Searching for novel antifungal agents is an important aspect of the post-harvest citrus industry because of the lack of higher effective and low toxic antifungal agents. Herein, the effects of 2-methoxy-1,4-naphthoquinone (MNQ) on P. italicum and its mechanism were carried out by a series of methods. MNQ had a significant anti-P. italicum effect with an MIC value of $5.0 \mu \mathrm{g} / \mathrm{mL}$. The label-free protein profiling under different MNQ conditions identified a total of 3037 proteins in the control group and the treatment group. Among them, there were 129 differentially expressed proteins (DEPs, up-regulated $>$ 2.0-fold or down-regulated $<0.5$-fold, $p<0.05$ ), 19 up-regulated proteins, 26 down-regulated proteins, and 67 proteins that were specific for the treatment group and another 17 proteins that were specific for the control group. Of these, 83 proteins were sub-categorized into 23 hierarchically-structured GO classifications. Most of the identified DEPs were involved in molecular function (47\%), meanwhile 27\% DEPs were involved in the cellular component and $26 \%$ DEPs were involved in the biological process. Twenty-eight proteins identified for differential metabolic pathways by KEGG were sub-categorized into 60 classifications. Functional characterization by GO and KEGG enrichment results suggests that the DEPs are mainly related to energy generation (mitochondrial carrier protein, glycoside hydrolase, acyl-CoA dehydrogenase, and ribulose-phosphate 3-epimerase), NADPH supply (enolase, pyruvate carboxylase), oxidative stress (catalase, glutathione synthetase), and pentose phosphate pathway (ribulose-phosphate 3-epimerase and xylulose 5-phosphate). Three of the down-regulated proteins selected randomly the nitro-reductase family protein, mono-oxygenase, and cytochrome P450 were verified using parallel reaction monitoring. These findings illustrated that MNQ may inhibit $P$. italicum by disrupting the metabolic processes, especially in energy metabolism and stimulus response that are both critical for the growth of the fungus. In conclusion, based on the molecular mechanisms, MNQ can be developed as a potential anti-fungi agent against P. italicum.
\end{abstract}

Keywords: Penicillium italicum; 2-methoxy-1,4-naphthoquinone; proteomics; mechanism; label-free quantitative 


\section{Introduction}

Plant pathogenic fungi negatively affects a large number of important fruits during the growing season and throughout post-harvest storage that cause serious losses of yield and quality for a number of fruits worldwide [1,2]. For instance, $10 \%$ to $30 \%$ of citrus fruit loss is caused by blue mold disease throughout the world [3]. One of the most usual post-harvest fungal diseases of citrus fruits is blue mold caused by Penicillium italicum. Agricultural practices and biological measures only provided limited relief against this disease. Thus, a large number of commercial fungicides were used to control the blue mold [4]. Application of numerous chemical synthetic fungicides is the major method to control P. italicum of citrus. However, the application of synthetic fungicides has been increasingly restricted because of a series of severe issues that arose from these chemical synthetic fungicides, such as residues of toxic compounds, environmental pollution, pathogen resistant development, and health hazard problems [4]. Compared to chemical synthetic antifungal agents, natural compounds are generally found to be safe due to less toxicity or no toxicity. It is, therefore, urgent to explore novel effective and non-toxic or less toxic antifungal agents with new modes of action. The numbers of research studies have reported the antifungal effects of natural antifungal compounds for restraining postharvest blue mold caused by P. italicum [3,5-8].

A 2-methoxy-1,4-naphthoquinone (MNQ) (Figure 1) is a naturally occurring phytochemical isolated from a traditional Chinese medicinal plant, Impatiens balsamina Linn [9]. Previous studies showed that MNQ possessed diverse biological activities including anti-cancer [10], anti-metastatic [11] , and anti-bacterial [12] properties. However, there is still a lack of more data about the antifungal activities of this 1,4-naphthoquinone derivative $[10,13]$. Nonetheless, our present investigation indicated that the MNQ had a significant anti-fungal activity against $P$. italicum as a promising anti-fungal precursor. However, the possible antifungal molecular mechanisms of MNQ P. italicum have not been investigated yet. Thus, the possible mechanisms involving changes of morphological, changes of proteins and pathways, and the energy deficit in P. italicum should be further investigated because the biomolecules functionally govern cellular processes and, ultimately, dictate the biological phenotypes, proteins that are primary targets of drug discovery [11], and the differentially expressed proteins (DEPs). These offer clues on the proteins and pathways affected by a drug treatment [14].

In this study, we aimed to investigate the modulatory effects of MNQ toward the P. italicum proteome by using a label-free quantitative proteomic approach to identify proteins with significantly changed expression profiles, to confirm their functions in the MNQ-treated P. italicum. Moreover, three selected proteins related to oxidative stress and polycyclic aromatic hydrocarbon degradation were also confirmed using parallel reaction monitoring (PRM) analysis. Ultimately, these findings will contribute to our further understanding of the possible new molecular action of MNQ against P. italicum.

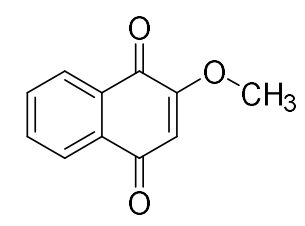

Figure 1. 2-Methoxy-1,4-naphthoquinone (MNQ).

\section{Results}

\subsection{Effects of MNQ on P. italicum}

The inhibitory effect of MNQ on P. italicum was carried out using a mycelial growth rate method. As shown in Table 1, MNQ at $1.0 \mu \mathrm{g} / \mathrm{mL}$ showed a blank antifungal activity against $P$. italicum. When the concentrations of MNQ are at 2.0, 4.0, and $6.0 \mu \mathrm{g} / \mathrm{mL}$, MNQ displayed a high anti-fungal activity against $P$. italicum. Among them, MNQ at $6.0 \mu \mathrm{g} / \mathrm{mL}$ exhibited a stronger antifungal activity against 
P. italicum. As depicted in Figure 2, P. italicum mycelial growth showed a declining tendency with the increasing concentrations of MNQ. The MIC value was defined as the lowest MNQ concentration that completely inhibited the growth of $P$. italicum after 48 hours of incubation at $28{ }^{\circ} \mathrm{C}$ [15]. MNQ showed a significant anti-P. italicum effect with an MIC value of $5.0 \mu \mathrm{g} / \mathrm{mL}$ (Figure S1).

Table 1. Effect of different MNQ concentrations on mycelial growth of P. italicum ${ }^{1}$.

\begin{tabular}{ccc}
\hline Concentration $(\mu \mathrm{g} / \mathrm{mL})$ & Mycelial Diameter $(\mathbf{m m})$ & I (\%) \\
\hline CK & $33.83 \pm 0.54^{\mathrm{a}}$ & - \\
0.0 & $32.67 \pm 0.56^{\mathrm{a}}$ & $3.45 \pm 1.65^{\mathrm{c}}$ \\
1.0 & $30.83 \pm 0.54^{\mathrm{a}}$ & $8.87 \pm 1.60^{\mathrm{c}}$ \\
2.0 & $17.33 \pm 2.30^{\mathrm{b}}$ & $48.77 \pm 6.81^{\mathrm{b}}$ \\
4.0 & $2.33 \pm 0.80^{\mathrm{c}}$ & $93.10 \pm 2.37^{\mathrm{a}}$ \\
6.0 & $0.83 \pm 0.17^{\mathrm{c}}$ & $97.54 \pm 0.49^{\mathrm{a}}$
\end{tabular}

${ }^{1}$ Mycelial growth was measured after incubation at $28^{\circ} \mathrm{C}$ for seven days. The date presented are the means \pm S.E. $(n=6) .{ }^{a-c}$ The column with different lowercase letters between different concentrations indicates significant differences, according to Duncan's test $(p<0.05)$.

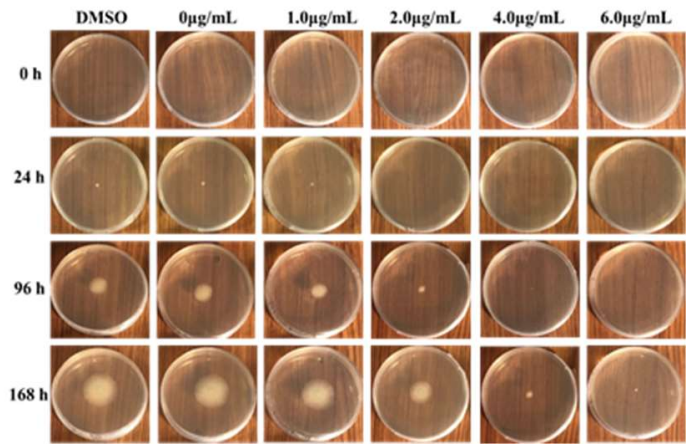

Figure 2. Inhibition of mycelial growth of P. italicum by MNQ.

\subsection{Light Microscopy Observation}

Light microscopy of the control P. italicum mycelia grown on PDB showed a normal, filamentous, and homogeneous mycelial morphology (Figure 3a). By contrast, the mycelia treated with $2.0 \mu \mathrm{g} / \mathrm{mL}$ of MNQ showed a massive distortion and abnormal enlargement of the growing point. Meanwhile, Figure $3 b, c$ showed that the MNQ-treated mycelia significantly altered the mycelial morphology of P. italicum, including breakage and malformation (highlighted with blue arrows). Clearly, MNQ treatment resulted in the damage to P. italicum mycelia (magnification is 400 times).

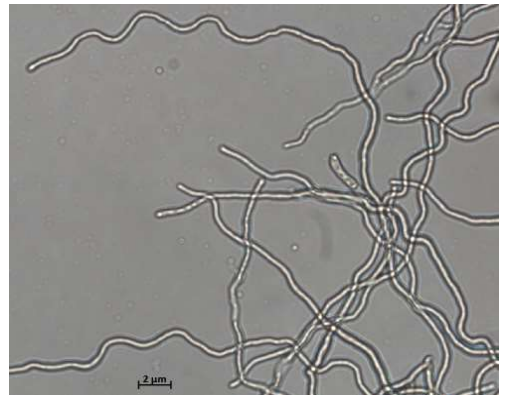

a

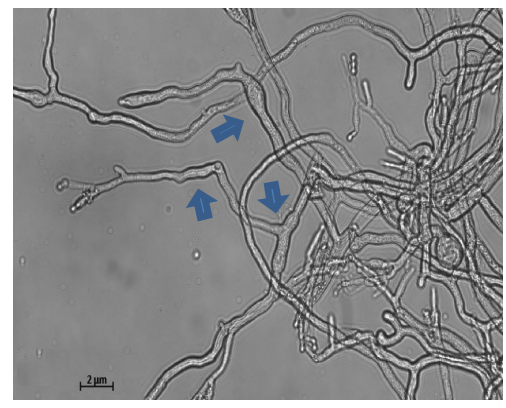

b

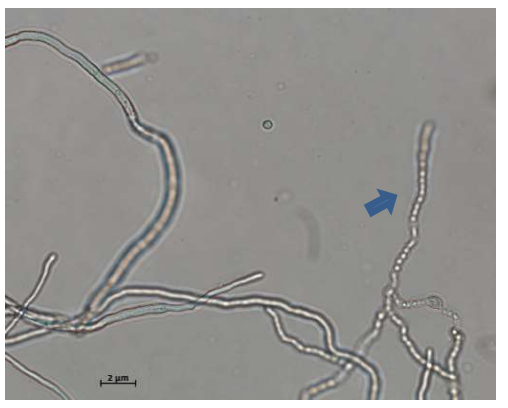

Figure 3. Light microscopy observation of P. italicum mycelial morphology (96 h). (a) P. italicum in the control group, (b) and (c) P. italicum in the treatment group (magnification is 400 times). 


\subsection{Label-Free Proteomic Based Protein Identification in the Treatment Group and Control Group}

Quantitative proteomic analysis of mycelia samples from the treatment group and control group was performed using the label-free proteomic analysis method. In total, 3037 proteins were identified with a $1 \%$ false discovery rate (FDR) (Table S1). Figure 4 shows the total numbers of differentially expressed proteins in the treatment group and the control group. Figure 4a shows the volcano plot for the differentially expressed proteins (DEPs) in the treatment group and the DEPs (up-regulated $>2.0$-fold or down-regulated $<0.5$-fold, $p<0.05$ ) highlight in a pink color. All the DEPs are listed in Table 2. The Venn diagram in Figure $4 \mathrm{~b}$ shows the number of proteins that are unique to the treatment group or the control group. As shown in Figure $4 \mathrm{~b}$, there were 2854 proteins both expressed in the treatment group and the control group, 139 proteins were unique to the treatment group when compared to 44 for the control group. A total of 129 proteins showed significant changes in expression. Compared with the control group, 45 proteins (19 up-regulated and 26 down-regulated) were significantly changed in abundance in the treatment group (Table 3). Meanwhile, 67 newly arising proteins were identified in the treatment group, but not found in the control group, and 17 proteins were undetectable in the treatment group while observed in the control group. Hierarchical cluster analysis was performed for all the DEPs for the treatment group and the control group (Figure 5). As shown in Figure 5, it was easy to note that the differentially expressed proteins in the treatment group did not cluster together with the one in the control group.

Table 2. The DEPs in different groups.

\begin{tabular}{|c|c|c|c|c|}
\hline Protein & Protein Name & Gene Name & $\begin{array}{c}\text { Fold } \\
\text { Changes } 1\end{array}$ & GO Category $^{2}$ \\
\hline A0A0A2KI00 & Uncharacterized protein & PITC_013530 & 9.66 & MF \\
\hline A0A0A2KQ56 & Uncharacterized protein & PITC_017440 & 5.80 & \\
\hline A0A0A2LĀ04 & Ribulose-phosphate 3-epimerase & PITC_011800 & 3.84 & $\mathrm{BP}, \mathrm{MF}$ \\
\hline A0A0A2KBU2 & Hydrophobin & PITC_015600 & 3.83 & $\mathrm{MF}, \mathrm{CC}$ \\
\hline A0A0A2KT64 & Uncharacterized protein & PITC_065480 & 3.15 & \\
\hline A0A0A2KL24 & Uncharacterized protein & PITC_064010 & 2.99 & \\
\hline A0A0A2LAT4 & Uncharacterized protein & PITC_037340 & 2.79 & \\
\hline A0A0A2KR85 & Uncharacterized protein & PITC_014180 & 2.76 & \\
\hline A0A0A2KVZ5 & Uncharacterized protein & PITC_028500 & 2.72 & \\
\hline A0A0A2KMP8 & Uncharacterized protein & PITC_017400 & 2.67 & \\
\hline A0A0A2L522 & Mitochondrial carrier protein & PITC_038210 & 2.51 & $\mathrm{MF}, \mathrm{CC}$ \\
\hline $\mathrm{A} 0 \mathrm{~A} 0 \mathrm{~A} 2 \mathrm{KX} 25$ & Uncharacterized protein & PITC_051360 & 2.37 & \\
\hline A0A0A2L8T3 & Uncharacterized protein & PITC_098640 & 2.32 & \\
\hline A0A0A2L2N9 & HEAT, type 2 & PITC_085160 & 2.10 & \\
\hline A0A0A2L2V7 & Acyl-CoA dehydrogenase, $\mathrm{N}$-terminal & PITC_066160 & 2.10 & MF \\
\hline A0A0A2LCB9 & Glycoside hydrolase, family 28 & PITC_005000 & 2.10 & $\mathrm{BP}, \mathrm{MF}, \mathrm{CC}$ \\
\hline A0A0A2LAG1 & $\begin{array}{l}\text { Xylulose 5-phosphate/Fructose 6-phosphate } \\
\text { phosphoketolase, N-terminal }\end{array}$ & PITC_003850 & 2.10 & $\mathrm{BP}, \mathrm{MF}$ \\
\hline A0A0A2L8I5 & Glucose-repressible protein Grg1 & PITC_061580 & 2.05 & \\
\hline A0A0A2L934 & Polyketide synthase, enoylreductase & PITC_030400 & 2.04 & MF \\
\hline A0A0A2LBT9 & CDR ABC transporter & PITC_091640 & 0.49 & $\mathrm{MF}, \mathrm{CC}$ \\
\hline A0A0A2KM09 & ATPase, AAA-type, core & PITC_028850 & 0.48 & MF \\
\hline A0A0A2KZ16 & $\begin{array}{l}\text { Mandelate racemase/muconate lactonizing } \\
\text { enzyme }\end{array}$ & PITC_098150 & 0.48 & $\mathrm{BP}, \mathrm{MF}$ \\
\hline A0A0A2KNF6 & Cytochrome P450 & PITC_065080 & 0.47 & $\mathrm{BP}, \mathrm{MF}$ \\
\hline A0A0A2LD14 & Short-chain dehydrogenase/reductase SDR & PITC_006840 & 0.46 & \\
\hline A0A0A2LAZ8 & Uncharacterized protein & PITC_023560 & 0.45 & $\mathrm{CC}$ \\
\hline A0A0A2KLM8 & Aldo/keto reductase & PITC_048920 & 0.43 & MF \\
\hline A0A0A2L925 & $\mathrm{ABC}$ transporter, integral membrane type 1 & PITC_030250 & 0.41 & $\mathrm{MF}, \mathrm{CC}$ \\
\hline A0A0A2L7S7 & Reverse transcriptase & PITC_011060 & 0.38 & MF \\
\hline A0A0A2L743 & Uncharacterized protein & PITC_032240 & 0.35 & MF \\
\hline A0A0A2KIE8 & Male sterility, NAD-binding & PITC_056110 & 0.34 & MF \\
\hline A0A0A2LCN6 & Short-chain dehydrogenase/reductase SDR & PITC_019130 & 0.31 & \\
\hline A0A0A2LGP0 & Carbon-nitrogen hydrolase & PITC_029870 & 0.30 & $\mathrm{BP}, \mathrm{MF}$ \\
\hline
\end{tabular}


Table 2. Cont.

\begin{tabular}{|c|c|c|c|c|}
\hline Protein & Protein Name & Gene Name & $\begin{array}{c}\text { Fold } \\
\text { Changes } 1\end{array}$ & GO Category ${ }^{2}$ \\
\hline A0A0A2KZU8 & Peptidase M20 & PITC_086250 & 0.23 & MF \\
\hline A0A0A2LFP8 & O-methyltransferase, family 3 & PITC_025440 & 0.21 & MF \\
\hline A0A0A2L830 & ThiJ/PfpI & PITC_001680 & 0.14 & \\
\hline A0A0A2L1V6 & $\begin{array}{l}\text { N-acyl-phosphatidylethanolamine- } \\
\text { hydrolyzing phospholipase D }\end{array}$ & PITC_051890 & 0.12 & MF \\
\hline A0A0A2LCF5 & $\begin{array}{l}\text { Acyl-transferase/acyl-hydrolase/ } \\
\text { lysophospholipase }\end{array}$ & PITC_005350 & 0.08 & MF \\
\hline A0A0A2L5Z5 & Uncharacterized protein & PITC_002480 & 0.08 & \\
\hline A0A0A2L3A1 & Uncharacterized protein & PITC_038310 & 0.07 & \\
\hline A0A0A2LCE5 & Uncharacterized protein & PITC_005250 & 0.06 & \\
\hline A0A0A2LAC2 & Uncharacterized protein & PITC_005360 & 0.04 & \\
\hline A0A0A2LKC5 & Monooxygenase, FAD-binding & PITC_005370 & 0.03 & $\mathrm{MF}, \mathrm{CC}$ \\
\hline A0A0A2L9W9 & Uncharacterized protein & PITC_005390 & 0.03 & $\mathrm{BP}, \mathrm{MF}$ \\
\hline A0A0A2KD20 & Uncharacterized protein & PITC_008180 & 0.03 & $\mathrm{BP}, \mathrm{MF}$ \\
\hline A0A0A2LCH9 & Uncharacterized protein & PITC_005280 & 0.03 & \\
\hline A0A0A2LEG0 & E3 ubiquitin protein ligase & PITC_068020 & + & $\mathrm{BP}, \mathrm{MF}, \mathrm{CC}$ \\
\hline A0A0A2KL74 & Uncharacterized protein & PITC_064410 & + & \\
\hline A0A0A2L3H1 & Kinetochore-Ndc80 subunit Spc24 & PITC_084180 & + & \\
\hline A0A0A2LNS4 & Zinc finger, RING-type & PITC_024830 & + & MF \\
\hline A0A0A2KNZ0 & $\begin{array}{l}\text { Translation elongation factor } \\
\text { EF1B/ribosomal protein S6 }\end{array}$ & PITC_014590 & + & $\mathrm{MF}, \mathrm{CC}$ \\
\hline A0A0A2KWT6 & Ribosome-releasing factor 2, mitochondrial & MEF2 & + & $\mathrm{BP}, \mathrm{MF}, \mathrm{CC}$ \\
\hline A0A0A2LC54 & $\begin{array}{l}\text { Peptidase C19, ubiquitin carboxyl-terminal } \\
\text { hydrolase } 2\end{array}$ & PITC_059690 & + & $\mathrm{BP}, \mathrm{MF}$ \\
\hline A0A0A2LG71 & Pectin lyase fold/virulence factor & PITC_050450 & + & MF \\
\hline A0A0A2L5T7 & Uncharacterized protein & PITC_001930 & + & $\mathrm{BP}$ \\
\hline A0A0A2K9T6 & $\begin{array}{l}\text { Uncharacterized conserved protein } \\
\text { UCP022603 }\end{array}$ & PITC_093160 & + & \\
\hline A0A0A2K9G7 & Glycoside hydrolase, superfamily & PITC_049080 & + & $\mathrm{BP}, \mathrm{MF}$ \\
\hline A0A0A2LF07 & CheY-like superfamily & PITC_061050 & + & MF \\
\hline A0A0A2LN85 & Taxilin family & PITC_010570 & + & MF \\
\hline $\mathrm{A} 0 \mathrm{~A} 0 \mathrm{~A} 2 \mathrm{~K} Y 31$ & Beta-glucosidase & PITC_028190 & + & $\mathrm{BP}, \mathrm{MF}$ \\
\hline A0A0A2KE07 & $\begin{array}{l}\text { Chromatin-remodeling complex, RSC } \\
\text { SWI/SNF subunit Rsc7/Swp82 }\end{array}$ & PITC_055960 & + & \\
\hline A0A0A2LB02 & RNA polymerase II subunit A & PITC_092370 & + & $\mathrm{BP}, \mathrm{MF}, \mathrm{CC}$ \\
\hline A0A0A2L857 & Transcription factor, MADS-box & PITC_001660 & + & $\mathrm{BP}, \mathrm{MF}, \mathrm{CC}$ \\
\hline A0A0A2L6J4 & $\begin{array}{l}\text { Neurolysin/Thimet oligopeptidase, } \\
\text { N-terminal }\end{array}$ & PITC_084000 & + & $\mathrm{BP}, \mathrm{MF}, \mathrm{CC}$ \\
\hline A0A0A2KT14 & Monopolin complex, subunit Csm1/Pcs1 & PITC_066000 & + & \\
\hline A0A0A2LE82 & Uncharacterized protein & PITC_037500 & + & \\
\hline A0A0A2LBD7 & Sof1-like protein & PITC_089150 & + & \\
\hline A0A0A2L5N2 & Striatin, N-terminal & PITC_021600 & + & \\
\hline A0A0A2L4U0 & $\begin{array}{l}\text { tRNA-dihydrouridine(47)synthase } \\
{[\mathrm{NAD}(\mathrm{P})(+)]}\end{array}$ & PITC_047170 & + & MF \\
\hline A0A0A2L4G7 & $\begin{array}{l}\text { Phosphatidylserine decarboxylase } \\
\text { proenzyme 1, mitochondrial }\end{array}$ & PSD1 & + & $\mathrm{BP}, \mathrm{MF}, \mathrm{CC}$ \\
\hline A0A0A2KS93 & BolA protein & PITC_042910 & + & \\
\hline A0A0A2LEA3 & Uncharacterized protein & PITC_034190 & + & \\
\hline A0A0A2KWV6 & Sensitivity to Red Light Reduced-like, SRR1 & PITC_077860 & + & \\
\hline A0A0A2L4C5 & Poly(A) polymerase & PITC_097130 & + & $\mathrm{BP}, \mathrm{MF}, \mathrm{CC}$ \\
\hline A0A0A2L1S8 & Heme-containing dehydratase & PITC_040090 & + & \\
\hline A0A0A2L7N4 & $\begin{array}{l}\text { Winged helix-turn-helix transcription } \\
\text { repressor DNA-binding }\end{array}$ & PITC_006550 & + & $\mathrm{BP}, \mathrm{MF}, \mathrm{CC}$ \\
\hline A0A0A2KI48 & Aldolase-type TIM barrel & PITC_009330 & + & MF \\
\hline A0A0A2KWA6 & Putative domain, di-copper center & PITC_096580 & + & MF \\
\hline A0A0A2LFQ2 & Uncharacterized protein & PITC_025560 & + & $\mathrm{CC}$ \\
\hline A0A0A2LAP4 & Uncharacterized protein & PITC_036940 & + & \\
\hline A0A0A2KHA2 & $\begin{array}{l}\text { DNA polymerase III, clamp loader complex, } \\
\text { gamma/delta/delta subunit, C-terminal }\end{array}$ & PITC_071920 & + & $\mathrm{BP}, \mathrm{MF}$ \\
\hline A0A0A2LFW6 & $\begin{array}{l}\text { Catalase, mono-functional, } \\
\text { heme-containing }\end{array}$ & PITC_041140 & + & $\mathrm{BP}, \mathrm{MF}$ \\
\hline A0A0A2L4V0 & Sas10/Utp3/C1D & PITC_084500 & + & \\
\hline
\end{tabular}


Table 2. Cont.

\begin{tabular}{|c|c|c|c|c|}
\hline Protein & Protein Name & Gene Name & $\begin{array}{c}\text { Fold } \\
\text { Changes } 1\end{array}$ & GO Category ${ }^{2}$ \\
\hline A0A0A2KMY7 & PfkB & PITC_046750 & + & \\
\hline A0A0A2L452 & Blastomyces yeast-phase-specific protein & PITC_083580 & + & \\
\hline A0A0A2LFY2 & $\begin{array}{l}\text { Outer membrane protein, IML2, } \\
\text { mitochondrial/Tetratricopeptide repeat } \\
\text { protein } 39\end{array}$ & PITC_041270 & + & $\mathrm{CC}$ \\
\hline A0A0A2L4F0 & $\begin{array}{l}\text { Vacuolar protein sorting-associated protein } \\
28\end{array}$ & PITC_032200 & + & $\mathrm{BP}, \mathrm{CC}$ \\
\hline A0A0A2KNJ7 & Ferritin & PITC_095310 & + & $\mathrm{BP}, \mathrm{MF}, \mathrm{CC}$ \\
\hline A0A0A2KCE3 & Uncharacterized protein & PITC_093200 & + & \\
\hline A0A0A2L328 & CheY-like superfamily & PITC_099880 & + & $\mathrm{BP}, \mathrm{MF}$ \\
\hline A0A0A2KWF5 & Ribosomal protein L53, mitochondrial & PITC_063020 & + & $\mathrm{CC}$ \\
\hline A0A0A2LGC1 & Uncharacterized protein & PITC_036010 & + & \\
\hline A0A0A2KAJ2 & Sec1-like protein & PITC_055020 & + & $\mathrm{BP}, \mathrm{CC}$ \\
\hline A0A0A2KLU4 & $\begin{array}{l}\text { H/ACA ribonucleoprotein complex, } \\
\text { subunit Nop10 }\end{array}$ & PITC_015880 & + & $\mathrm{BP}, \mathrm{MF}$ \\
\hline A0A0A2LB80 & Uncharacterized protein & PITC_088770 & + & MF \\
\hline A0A0A2L283 & $\begin{array}{l}\text { Vacuole morphology and inheritance } \\
\text { protein } 14\end{array}$ & PITC_085800 & + & $\mathrm{BP}, \mathrm{CC}$ \\
\hline A0A0A2LJG8 & Uncharacterized protein & PITC_091330 & + & \\
\hline A0A0A2LDT3 & Scytalone dehydratase & PITC_055360 & + & $\mathrm{BP}, \mathrm{MF}$ \\
\hline А0А0А2КРК9 & Alpha/gamma-adaptin-binding protein p34 & PITC_045290 & + & \\
\hline A0A0A2LF46 & $\begin{array}{l}\text { Glutamyl-tRNA(Gln) amido-transferase } \\
\text { subunit B, mitochondrial }\end{array}$ & PITC_061230 & + & $\mathrm{BP}, \mathrm{MF}, \mathrm{CC}$ \\
\hline A0A0A2LDQ9 & Uncharacterized protein & PITC_055380 & + & \\
\hline A0A0A2KLL9 & Acyl-transferase/acyl-hydrolase/lysophospholip & odseTC_048820 & + & MF \\
\hline A0A0A2KPR9 & Uncharacterized protein & PITC_054110 & + & $\mathrm{CC}$ \\
\hline A0A0A2KYQ5 & Magnesium transporter & PITC_061420 & + & $\mathrm{CC}$ \\
\hline A0A0A2KM68 & Uncharacterized protein & PITC_079240 & + & \\
\hline A0A0A2LE28 & Carboxymuconolactone decarboxylase & PITC_044010 & + & MF \\
\hline A0A0A2LBC3 & Uncharacterized protein & PITC_016760 & + & \\
\hline A0A0A2LPW9 & Uncharacterized protein & PITC_059180 & + & \\
\hline A0A0A2KYR5 & Uncharacterized protein & PITC_014450 & + & \\
\hline A0A0A2KРB6 & Exon junction complex, Pym & PITC_045720 & + & $\mathrm{BP}$ \\
\hline A0A0A2L3C0 & Uncharacterized protein & PITC_002320 & + & \\
\hline A0A0A2LDR6 & Translation Initiation factor eIF-4e & PITC_055210 & + & $\mathrm{MF}, \mathrm{CC}$ \\
\hline A0A0A2L3Q9 & Uncharacterized protein & PITC_035540 & + & \\
\hline A0A0A2K7Z3 & RTA-like protein & PITC_013070 & - & $\mathrm{CC}$ \\
\hline А0A0A2K9K0 & Uncharacterized protein & PITC_049430 & - & $\mathrm{CC}$ \\
\hline A0A0A2КC81 & Zinc finger, $\mathrm{CCCH}$-type & PITC_079160 & - & MF \\
\hline A0A0A2KRX9 & FAD dependent oxidoreductase & PITC_020210 & - & MF \\
\hline A0A0A2КTM9 & AP-3 complex subunit delta & PITC_064680 & - & $\mathrm{BP}, \mathrm{CC}$ \\
\hline A0A0A2KTQ5 & TRAM1-like protein & PITC_000730 & - & $\mathrm{CC}$ \\
\hline A0A0A2KY77 & MAP kinase & PITC_057580 & - & $\mathrm{BP}, \mathrm{MF}, \mathrm{CC}$ \\
\hline A0A0A2L001 & Uncharacterized protein & PITC_075040 & - & $\mathrm{MF}, \mathrm{CC}$ \\
\hline A0A0A2L1F3 & $\begin{array}{l}\text { Membrane-associated, } \\
\text { eicosanoid/glutathione metabolism protein } \\
\text { (MAPEG) }\end{array}$ & PITC_035700 & - & $\mathrm{CC}$ \\
\hline A0A0A2L3U6 & Uncharacterized protein & PITC_083660 & - & MF \\
\hline A0A0A2L4J0 & RNA recognition motif domain, eukaryote & PITC_097790 & - & $\mathrm{BP}, \mathrm{MF}, \mathrm{CC}$ \\
\hline A0A0A2L843 & Serine hydrolase FSH & PITC_001510 & - & MF \\
\hline A0A0A2L8X0 & $\begin{array}{l}\text { Glutamyl-tRNA synthetase, class Ib, } \\
\text { archaeal/eukaryotic cytosolic }\end{array}$ & PITC_073010 & - & $\mathrm{BP}, \mathrm{MF}, \mathrm{CC}$ \\
\hline A0A0A2L929 & Acyl-CoA dehydrogenase, $\mathrm{N}$-terminal & PITC_030080 & - & MF \\
\hline A0A0A2L9E5 & $\begin{array}{l}\text { Major facilitator superfamily domain, } \\
\text { general substrate transporter }\end{array}$ & PITC_090610 & - & $\mathrm{BP}, \mathrm{CC}$ \\
\hline A0A0A2LCH4 & $\begin{array}{l}\text { Major facilitator superfamily domain, } \\
\text { general substrate transporter }\end{array}$ & PITC_004620 & - & $\mathrm{MF}, \mathrm{CC}$ \\
\hline A0A0A2LEL6 & Tetratricopeptide-like helical & PITC_067660 & - & MF \\
\hline
\end{tabular}

${ }^{1}$ Up-regulated proteins are highlighted in red. Down-regulated proteins are highlighted in green. " + " stands for only detected in treatment group and "-" stands for only detected in the control group. ${ }^{2}$ BP was biological process, MF was molecular function, CC was cellular component. 
Table 3. Numbers of DEPs in the treatment group compared with the control group.

\begin{tabular}{ccc}
\hline \multirow{2}{*}{ Comparisons } & \multicolumn{2}{c}{ Number of Involved Proteins } \\
\cline { 2 - 3 } & Increased & Decreased \\
\hline Significantly changing in abundance & 19 & 26 \\
Newly arising/undetectable ${ }^{1}$ & 67 & 17 \\
\hline
\end{tabular}

${ }^{1}$ The proteins newly arising/undetectable in the treatment group were also treated as significantly up-regulated/ down-regulated.

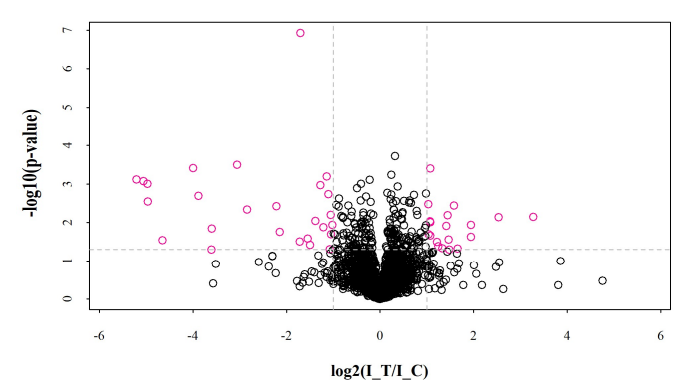

(a)

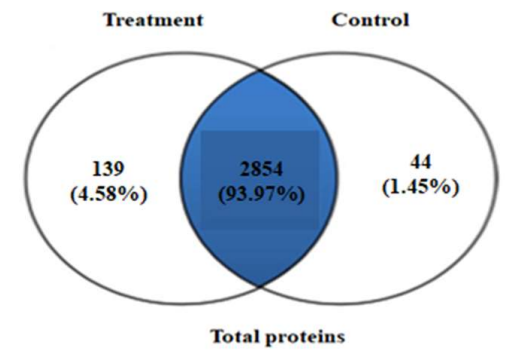

(b)

Figure 4. DEPs in different groups. (a) Volcano plot of DEPs, I-T was the treatment group. I-C was the control group. (b) Venn diagram of proteins in different groups.
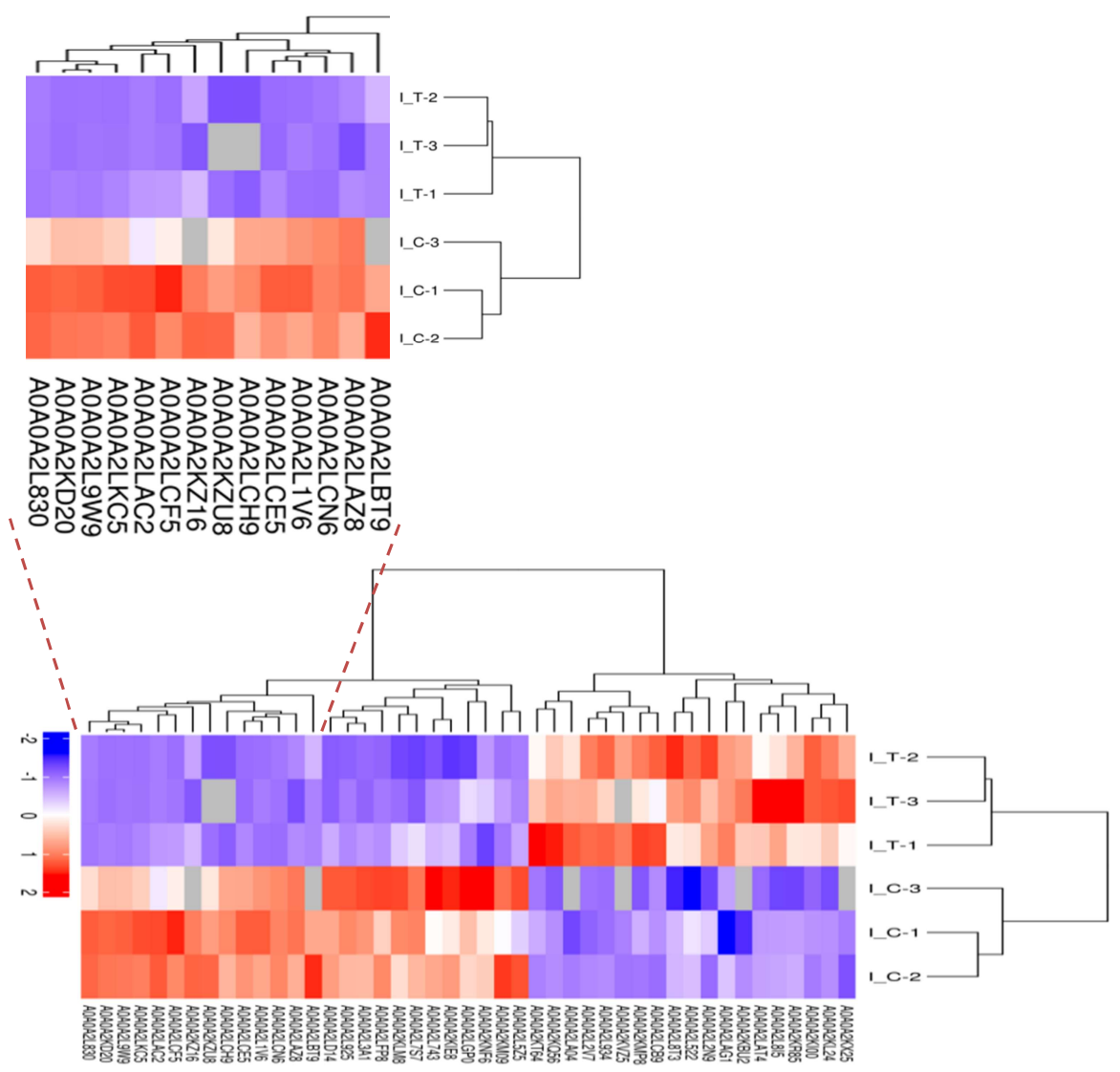

Figure 5. Hierarchical cluster analysis was conducted for all the DEPs. I-T was the treatment group. I-C was the control group. The numbers were the protein ID and could search in Table S1.

\subsection{Functional Annotation of Proteins}

To deduce the functionality and biological processes associated with the identified DEPs in the treatment group and control group, gene ontology (GO) analysis and Kyoto Encyclopedia of Genes 
and Genomes (KEGG) enrichments were performed. The GO and KEGG annotation of the identified proteins were carried out to comprehensively reflect the biological functions and significance of these proteins in various life activities. Functional annotation of all proteins obtained from the treatment group and control group revealed a sum of 129 differential proteins. Of these, 83 proteins were sub-categorized into 23 hierarchically-structured GO classifications. Twenty-eight proteins identified for differential metabolic pathways by KEGG were sub-categorized into 60 classifications (Figure 6).

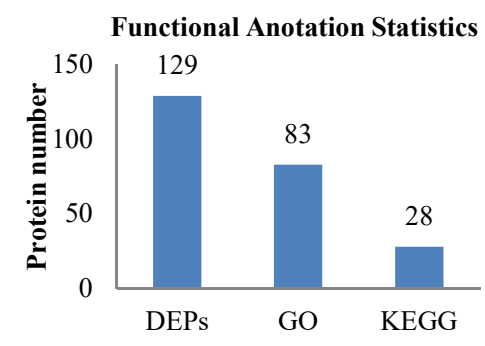

Figure 6. Statistical results of different functional annotations.

\subsubsection{Gene Ontology (GO) Annotation}

GO annotation gives a priority for a systematical analysis of the protein properties of targeted proteins [16]. In order to get a detailed description, GO was further categorized into three components e.g., biological process (BP), cellular component (CC), and molecular function (MF). The GO analysis revealed that the identified DEPs were associated with different molecular and biological processes. Most of the identified DEPs were involved in molecular function (47\%). Meanwhile 27\% DEPs were involved in the cellular component and $26 \%$ DEPs were involved in the biological process (Figure 7). The biological process was found to be highly enriched in the cellular process (35\%) and the metabolic process $(32 \%)$. At the cellular component level, the identified DEPs were linked to the membrane $(19 \%)$, membrane part $(19 \%)$, cell $(18 \%)$, cell part $(17 \%)$, and organelle $(14 \%)$. Similarly, catalytic activity $(53 \%)$ and binding (38\%) were most significantly expressed in the molecular function. Altogether, these results suggest that many proteins in P. italicum under MNQ treated might be involved in different metabolic and cellular processes and localize in different cell parts and organelles.

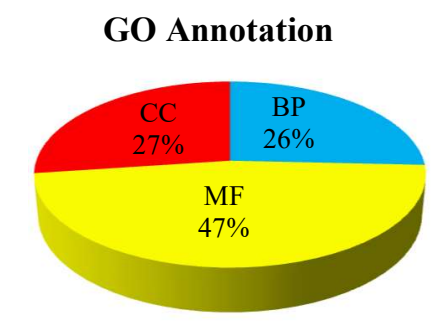

BP

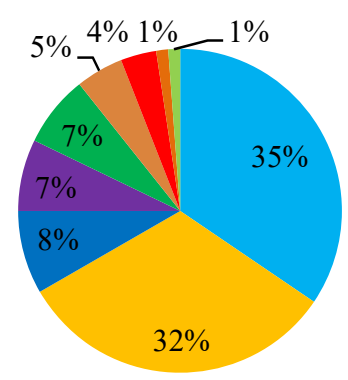

cellular process
metabolic process
- localization
response to stimulus
rellular component organization or biogenesis
- biological regulation
regulation of biological process
signaling
positive regulation of biological process

Figure 7. Cont. 
CC

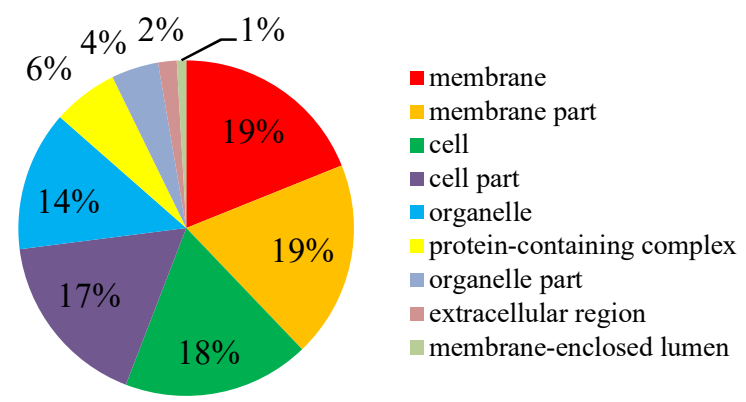

MF

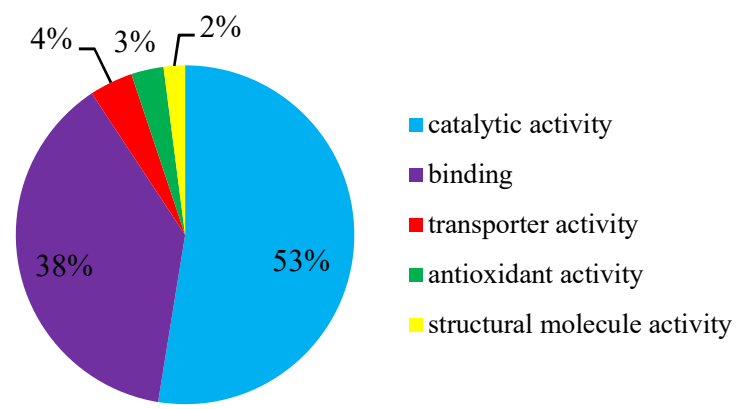

Figure 7. GO annotation for the DEPs.

\subsubsection{Metabolic Pathway Annotation}

The DEPs coordinate with each other to express their biological behavior. Thus, the pathway-based annotation broadens further exploration of their biological functions. The pathway analysis can determine important biochemical, ametabolic, and signaling pathways regulated by proteins. The KEGG database results indicated that the differential proteins participated in a total of 60 signaling pathways (Table 4). From these, the top 10 metabolic pathways were dioxin degradation, polycyclic aromatic hydrocarbon degradation, linoleic acid metabolism, betalain biosynthesis, sphingolipid metabolism, mineral absorption, longevity regulating pathway, pentose and glucuronate interconversions, MAPK signaling pathway-yeast, and the mRNA surveillance pathway (Figure S2).

Table 4. Pathways encompassed by the DEPs ${ }^{1}$.

\begin{tabular}{ll}
\hline Pathway & Protein Name \\
\hline Dioxin degradation & Monooxygenase, FAD-binding \\
Polycyclic aromatic hydrocarbon degradation & Monooxygenase, FAD-binding \\
Linoleic acid metabolism & Cytochrome P450 \\
Betalain biosynthesis & Putative domain, di-copper center \\
Sphingolipid metabolism & TRAM1-like protein \\
Mineral absorption & Ferritin \\
Longevity regulating pathway & Catalase, mono-functional, heme-containing \\
& Translation Initiation factor eIF-4e \\
Pentose and glucuronate interconversions & Ribulose-phosphate 3-epimerase \\
& Glycoside hydrolase, family 28 \\
MAPK signaling pathway - yeast & Transcription factor, MADS-box; \\
& Catalase, mono-functional, heme-containing; \\
& MAP kinase \\
mRNA surveillance pathway & RNA polymerase II subunit A; \\
& Poly(A) polymerase; \\
& Exon junction complex, Pym \\
\hline
\end{tabular}


Table 4. Cont.

\begin{tabular}{|c|c|}
\hline Pathway & Protein Name \\
\hline \multirow[b]{2}{*}{ Carbon fixation in photosynthetic organisms } & Ribulose-phosphate 3-epimerase; \\
\hline & $\begin{array}{l}\text { Xylulose 5-phosphate/Fructose 6-phosphate phosphoketolase, } \\
\text { N-terminal }\end{array}$ \\
\hline & Ribulose-phosphate 3-epimerase; \\
\hline Pentose phosphate pathway & $\begin{array}{l}\text { Xylulose 5-phosphate/Fructose 6-phosphate phosphoketolase, } \\
\text { N-terminal }\end{array}$ \\
\hline Phenylpropanoid biosynthesis & Beta-glucosidase \\
\hline Naphthalene degradation & Monooxygenase, FAD-binding \\
\hline MAPK signaling pathway - plant & Catalase, mono-functional, heme-containing \\
\hline Chemical carcinogenesis & $\begin{array}{l}\text { Membrane-associated, eicosanoid/glutathione metabolism } \\
\text { (MAPEG) protein }\end{array}$ \\
\hline Mismatch repair & $\begin{array}{l}\text { DNA polymerase III, clamp loader complex, gamma/delta/delta } \\
\text { subunit, C-terminal }\end{array}$ \\
\hline Ferroptosis & Ferritin \\
\hline Isoquinoline alkaloid biosynthesis & Putative domain, di-copper center \\
\hline Cyanoamino acid metabolism & Beta-glucosidase \\
\hline EGFR tyrosine kinase inhibitor resistance & Translation Initiation factor eIF-4e \\
\hline Drug metabolism - cytochrome P450 & $\begin{array}{l}\text { Membrane-associated, eicosanoid/glutathione metabolism } \\
\text { (MAPEG) protein }\end{array}$ \\
\hline Amyotrophic lateral sclerosis (ALS) & Catalase, mono-functional, heme-containing \\
\hline DNA replication & $\begin{array}{l}\text { DNA polymerase III, clamp loader complex, gamma/delta/delta } \\
\text { subunit, C-terminal }\end{array}$ \\
\hline Metabolism of xenobiotics by cytochrome P450 & $\begin{array}{l}\text { Membrane-associated, eicosanoid/glutathione metabolism } \\
\text { (MAPEG) protein }\end{array}$ \\
\hline Melanogenesis & Putative domain, di-copper centre \\
\hline Platinum drug resistance & $\begin{array}{l}\text { Membrane-associated, eicosanoid/glutathione metabolism } \\
\text { (MAPEG) protein }\end{array}$ \\
\hline Galactose metabolism & Mandelate racemase/muconate lactonizing enzyme \\
\hline Two-component system & MAP kinase \\
\hline MAPK signaling pathway - fly & Striatin, N-terminal \\
\hline Nucleotide excision repair & $\begin{array}{l}\text { DNA polymerase III, clamp loader complex, gamma/delta/delta } \\
\text { subunit, C-terminal }\end{array}$ \\
\hline HIF-1 signaling pathway & Translation Initiation factor eIF-4e \\
\hline Hepatocellular carcinoma & $\begin{array}{l}\text { Membrane-associated, eicosanoid/glutathione metabolism } \\
\text { (MAPEG) protein }\end{array}$ \\
\hline Lysosome & AP-3 complex subunit delta \\
\hline FoxO signaling pathway & Catalase, mono-functional, heme-containing \\
\hline Fluid shear stress and atherosclerosis & $\begin{array}{l}\text { Membrane-associated, eicosanoid/glutathione metabolism } \\
\text { (MAPEG) protein }\end{array}$ \\
\hline Longevity regulating pathway - worm & Catalase, mono-functional, heme-containing \\
\hline Drug metabolism - other enzymes & $\begin{array}{l}\text { Membrane-associated, eicosanoid/glutathione metabolism } \\
\text { (MAPEG) protein }\end{array}$ \\
\hline Necroptosis & Ferritin \\
\hline Longevity regulating pathway-multiple species & Catalase, mono-functional, heme-containing \\
\hline Human T-cell leukemia virus 1 infection & Vacuole morphology and inheritance protein 14 \\
\hline Glutathione metabolism & $\begin{array}{l}\text { Membrane-associated, eicosanoid/glutathione metabolism } \\
\text { (MAPEG) protein }\end{array}$ \\
\hline Tyrosine metabolism & Putative domain, di-copper center \\
\hline Tryptophan metabolism & Catalase, mono-functional, heme-containing \\
\hline Peroxisome & Catalase, mono-functional, heme-containing \\
\hline Glycerophospholipid metabolism & Phosphatidylserine decarboxylase proenzyme 1 , mitochondrial \\
\hline Ribosome biogenesis in eukaryotes & HEAT, type 2,H/ACA ribonucleoprotein complex, subunit Nop10 \\
\hline Insulin signaling pathway & Translation Initiation factor eIF-4e \\
\hline Starch and sucrose metabolism & Beta-glucosidase \\
\hline PI3K-Akt signaling pathway & Translation Initiation factor eIF-4e \\
\hline mTOR signaling pathway & Translation Initiation factor eIF-4e \\
\hline Viral carcinogenesis & Vacuole morphology and inheritance protein 14 \\
\hline Pathways in cancer & $\begin{array}{l}\text { Membrane-associated, eicosanoid/glutathione metabolism } \\
\text { (MAPEG) protein }\end{array}$ \\
\hline Amino sugar and nucleotide sugar metabolism & Glycoside hydrolase, superfamily \\
\hline Glyoxylate and dicarboxylate metabolism & Catalase, mono-functional, heme-containing \\
\hline
\end{tabular}


Table 4. Cont.

\begin{tabular}{ll}
\hline Pathway & Protein Name \\
\hline Aminoacyl-tRNA biosynthesis & Glutamyl-tRNA(Gln) amidotransferase subunit B, mitochondrial \\
RNA transport & Exon junction complex, Pym; \\
Autophagy-yeast & Translation Initiation factor eIF-4e \\
Endocytosis & Sec1-like protein \\
Spliceosome & Vacuolar protein sorting-associated protein 28 \\
\hline \multicolumn{1}{c}{${ }^{1}$ Up-regulated proteins are highlighted in red. Down-regulated proteins are highlighted in green. }
\end{tabular}

\subsection{PRM Verification of DEPS}

The PRM assay was applied to validate the selected proteins obtained in the label-free quantitative proteomics analysis. Only proteins that possessed unique peptide sequences were selected for PRM analysis because the signature peptides for target proteins must exhibit uniqueness [17]. Three of the proteins were selected at random for further verification. The PRM results showed that the abundance of nitroreductase family protein (from Metarhizium brunneum, identity 90.4\%), cytochrome P450, and monooxygenase changed in a consistent way with the proteomics results (Table 5). In general, three of the candidate proteins detected by PRM had changes consistent with the proteomics results.

Table 5. Comparison of the proteomics result and the PRM result of the three candidate proteins.

\begin{tabular}{ccccc}
\hline Protein Name & Gene Name & Signature Peptides & Proteomics Result $^{\mathbf{1}}$ & PRM Result $^{\mathbf{2}}$ \\
\hline $\begin{array}{c}\text { Nitro-reductase } \\
\text { family protein }\end{array}$ & PITC_008180 & $\begin{array}{c}\text { LGPLLQSHK } \\
\text { SISPALWEK }\end{array}$ & 0.03 & 0.05 \\
Cytochrome P450 & PITC_065080 & $\begin{array}{c}\text { AVLSDAVALVR } \\
\text { GALEEALQTYSGVR } \\
\text { QLENYDEVDDK } \\
\text { SDANTSNAYWNGFHPR }\end{array}$ & 0.47 & 0.35 \\
\hline
\end{tabular}

${ }^{1}$ Fold changes of protein abundance in proteomics result. Down-regulated proteins are highlighted in green. ${ }^{2}$ Fold
changes of protein abundance in PRM result. ${ }^{3}$ Nitroreductase family protein (from Metarhizium brunneum, $90.4 \%$ ).

\section{Discussion}

\subsection{Effects of MNQ on the Mycelial Growth and Morphology of P. italicum}

For a pathogen, a drug may prove fatal depending on the level of drug exposure (time and concentration). Our present study showed that the mycelial growths of $P$. italicum were decreased in a dose-dependent manner. MNQ treatment significantly reduced the mycelial growth of $P$. italicum (Table 1). However, microorganisms are extremely adaptable because their lifestyles require the swift phenotypic adaptation with a variety of changing environmental factors [18]. If the pathogenic fungi are not inhibited or killed by drug exposure, its will render the organism less susceptible to drug toxicity because the drug challenge may be met by adaptive responses [19].

Microscopic analyses showed a clear difference between the treatment group and control group mycelia of P. italicum. The MNQ $(2.0 \mu \mathrm{g} / \mathrm{mL})$ treated mycelia were inflated at the growing point. Meanwhile, those mycelia exposed to MNQ treatment were malformation and collapsed. The present study revealed that the prominence of mycelia decreased the mycelia grew, and the changes of mycelia may have been attributed to amplifying membrane permeability. It would result in the swelling of the mycelial tips, collapse of the cell wall, leakage of cell constituents, and, ultimately, mycelia growth was restricted or cell death (Figures 2 and 3). In a word, microscopy observation showed that MNQ resulted in an irregular variation of $P$. italicum mycelia, which indicates that the inhibitory effect of MNQ on P. italicum could be linked with membrane permeability changes modulated by the membrane lipid composition. Ergosterol is one of the main lipid molecules in the fungi cell membrane. It regulates membrane fluidity, permeability, and the activity of many membrane-bound enzymes [20]. 
Furthermore, the inhibition on ergosterol synthesis may result in changes of the cell wall structure and morphology [21]. Under the stress of the MNQ, it is more difficult for P. italicum to maintain cell wall integrity or to produce a new cell wall. The change of mycelial morphology suggested that MNQ can play an important role in destroying P. italicum viability.

\subsection{Proteins Related to Energy Generation and the NADPH Supply and Other Functions}

Proteomics results suggested that MNQ elicited a cellular response and some peculiar mechanisms that were very different between the treatment group and control group due to MNQ exposure is an environmental stress to a pathogen who must raise the response [19]. A fitting response to these adversities that might be caused by MNQ includes physiological and developmental changes, reprogramming of the resistance gene or proteins, the affection of energy generation, and the NADPH supply. Proteomics analysis revealed that MNQ treatment significantly up-regulated four energy generation related proteins including the mitochondrial carrier protein, glycoside hydrolase, acyl-CoA dehydrogenase, and ribulose-phosphate 3-epimerase (Table 2). The results showed that the mitochondrial carrier protein increased by 2.51-fold in the treatment group. The increase of the mitochondrial carrier protein may lead to accelerated material transport, which suggests that the biosynthesis and degradation rate in the mitochondria of cells were accelerated [22] because mitochondria play an important metabolic role in eukaryotes that generate the energy in the form of ATP [23]. In addition, the acyl-CoA dehydrogenase (ACAD) can catalyze $\alpha, \beta$-acyl-CoA esters dehydrogenation in the amino acid, and fatty acid catabolism [24]. Both acyl-CoA oxidases and ACAD that is bona fide peroxisomal proteins in fungi are the basic enzymatic repertoire of peroxisomes [25]. The increase of ACAD indicated that fatty acid and amino acid catabolism were active in the treatment group.

Meanwhile, there were five proteins up-regulated including enolase, pyruvate carboxylase, ATP-dependent 6-phosphofructokinase, malate synthase, and phosphoenolpyruvate carboxykinase that play a role in the NADPH supply (Table S1). Enolase, as a significant metabolic intermediate for ATP and NADH production, is a ubiquitous glycolytic enzyme involved in the glycolysis and gluconeogenesis pathways, and it catalyzes the reversible dehydration conversion of 2-phosphoglyceric acid into phosphoenolpyruvate [26]. In our study, the up-regulated enolase may play an important role in energy generation and cell apoptosis. NADPH plays a vital role in fatty acid synthesis. The change of NADPH may affect the cell integrity because phospholipids are the main content factors of the cell membrane [27]. Some of these enzymes including malic enzyme (ME) and 6-phosphogluconate dehydrogenase (6PGDH) also play important roles in generating NADPH/NADH. ME is a primary source of NADPH for de novo lipid biosynthesis and desaturation. Meanwhile, 6PGDH is one of the enzymes that catalyzes reactions generating NADPH in the oxidative pentose phosphate pathway [28]. We found that ME and 6PGDH increased 1.03-fold and 1.15-fold, but the expression difference was not consistent with the significance criteria (Table S1). It is reported that NADPH could prevent oxidative stress in the cell. For example, NADPH reduces glutathione through glutathione reductase because NADPH could convert $\mathrm{H}_{2} \mathrm{O}_{2}$ into $\mathrm{H}_{2} \mathrm{O}$ by glutathione peroxidase. If NADPH is absent, the $\mathrm{H}_{2} \mathrm{O}_{2}$ would be converted to hydroxyl-free radicals to attack the cell [27]. NADPH in the P. italicum might increase the fatty acid synthesis and oxidation resistance that may improve the defense during treated MNQ.

The stress condition tends to disrupt cell and organelle membranes and cause an ionic imbalance that stimulates the generation of reactive oxygen species (ROS) [29]. The generation of ROS leads to apoptosis [30]. Previous studies indicated that the antioxidant proteins were the first cellular defense against the oxidative stress. Glutathione transferase and dioxygenases may be related to the response of the fungus to oxidative stress caused by an ROS increase and ATP production [31]. Our proteomics analysis revealed that MNQ treatment up-regulated seven oxidative stress related proteins including catalase (CAT), acyl transferase, glutathione synthetase carboxymuconolactone decarboxylase, tRNA-dihydrouridine (47) synthase $[\mathrm{NAD}(\mathrm{P})(+)]$, polyketide 
synthase, and aldolase-type TIM barrel (Table 2). Antioxidant enzymes such as CAT was up-regulated when exposed to $\mathrm{MNQ}$, which shows its important role in detoxification of ROS. In addition, antioxidant enzymes against ROS, such as peroxidase and alcohol dehydrogenase were also up-regulated, but the expression difference did not meet the significance criteria when exposed to MNQ stress as compared to the control group (Table S1). Glutathione in fungi and some bacteria is an important antioxidant with a capability of preventing damage to important cellular constituents caused by ROS [32]. Glutathione as a substrate, is also contributed to the regeneration of other antioxidants [33]. Glutathione biosynthesis involves two sequential ATP dependent reactions, and is mediated by two enzymes $\gamma$-glutamylcysteine synthetase and glutathione synthetase (GS). Energy generation enhanced and GS increased 1.09-fold meant that glutathione increased in the treatment group. We hypothesized that the change of energy generation, NADPH supply, and oxidative stress affected the cell growth and mycelial morphology that was also confirmed by the P. italicum mycelial growth curve and microscopic analyses (Figures 2 and 4).

Among the pentose phosphate pathway (PPP), two enzymes called ribulose-phosphate 3-epimerase (RPE) and xylulose 5-phosphate were up-regulated. RPE can play a vital role in the development of a pool of NADPH, in the PPP that can convert monosaccharides, such as glucose, into the nucleotide precursor of pentose sugars. In addition, RPE can convert the ribulose-5-phosphate into xylulose 5-phosphate in the Calvin cycle [34]. RPE was identified with reversibly oxidized cysteines, which was another enzyme that uses ribulose-5-phosphate as the substrate. We found other published sources that reported the rpe (ribulose phosphate 3-epimerase gene)-disrupted mutant resulted in low cell growth and low inosine production on glucose and on gluconate [35]. Furthermore, RPE was up-regulated significantly, which suggests that PPP was significantly active in the treatment group. This pathway has been suggested as a drug target in trypanosomes [34].

According to the above analysis, we speculated that MNQ inhibited the growth of $P$. italicum by affecting the generation of energy and NADPH, which, thereby, affects the synthesis of fatty acids and amino acids. Meanwhile, PPP may be the target of MNQ for P. italicum, but the actual situation still needs to be further investigated.

\section{Materials and Methods}

\subsection{Microorganism and Medium}

P. italicum was provided by the South China Botanical Garden, Chinese Academy of Sciences (Guangzhou, China). P. italicum was cultured on potato dextrose agar (PDA, potato $200 \mathrm{~g} / \mathrm{L}$, agar $20 \mathrm{~g} / \mathrm{L}$, and dextrose $20 \mathrm{~g} / \mathrm{L}$ ) or potato dextrose broth (PDB, potato $200 \mathrm{~g} / \mathrm{L}$ and dextrose $20 \mathrm{~g} / \mathrm{L}$ ).

\subsection{MNQ Inhibition of P. italicum}

\subsubsection{Antifungal Assay}

The effects of MNQ on mycelial growth were measured as described by Myresiotis et al. [36]. MNQ was suspended in DMSO and the stock solution of MNQ $(10,000 \mu \mathrm{g} / \mathrm{mL})$ was added to the PDA media $(50 \mathrm{~mL})$ contained in conical flasks to obtain the desired concentrations of MNQ $(0,1.0,2.0$, 4.0, and $6.0 \mu \mathrm{g} / \mathrm{mL})$ in the media. The medium was poured into a set of three Petri dishes $(90 \mathrm{~mm}$ in diameter) under aseptic conditions. Then the plates were placed under UV light for solidification of the media. Meanwhile, we transferred the mycelia of P. italicum grown on PDA (about 7 days) to PDB in order to obtain conidial suspensions (about $1 \times 10^{5} \mathrm{CFU} / \mathrm{mL}$ ). After that, $1 \mu \mathrm{L}$ of P. italicum $\left(1 \times 10^{5} \mathrm{CFU} / \mathrm{mL}\right.$ conidial suspensions) were transferred to the center of the PDA plates. PDA media amended with DMSO $(20 \mu \mathrm{L})$ was used as the control. Each treatment in the experiment had three replicate plates, and was repeated twice. All cultivations were carried out at $28^{\circ} \mathrm{C}$. The inhibition of mycelial growth rate (\%) was calculated using the following formula [37].

$$
\mathrm{I}(\%)=(\mathrm{C}-\mathrm{T}) / \mathrm{C} \times 100 \%
$$


where $\mathrm{C}$ and $\mathrm{T}$ were the mean mycelium colony diameters of the control and the treatment and I was the inhibition of the mycelial growth rate (\%).

\subsubsection{Minimum Inhibitory Concentration (MIC) Tests}

The effects of MNQ on P. italicum were performed with a minimum inhibitory concentration (MIC) value [38]. MNQ was tested against $P$. italicum at different concentrations of 40.0, 20.0, 10.0, 5.0, 2.5, 1.25, 0.625 , and $0.3125 \mu \mathrm{g} / \mathrm{mL}$. The stock solution of MNQ $(10,000 \mu \mathrm{g} / \mathrm{mL})$ was first diluted to the highest concentration $(40 \mu \mathrm{g} / \mathrm{mL})$, and then serial two-fold dilution was made in a concentration range from 40.0 to $0.3125 \mu \mathrm{g} / \mathrm{mL}$. The solutions poured into $50 \mathrm{~mL}$ conical flasks containing melted PDA medium. Then the medium was poured into a set of three Petri dishes (60 $\mathrm{mm}$ in diameter) under aseptic conditions. The plates were placed under UV light for solidification of the media. After solidification, $20 \mu \mathrm{L}$ of conidial suspensions (about $1 \times 10^{5} \mathrm{CFU} / \mathrm{mL}$ ) were then smeared evenly onto the surface of the plates, aseptically. Lastly, all the culture plates were incubated at $28^{\circ} \mathrm{C}$ for $48 \mathrm{~h}$. Each treatment had three replicate plates, and the experiment was repeated twice.

\subsection{Cell Culture and MNQ Treatment}

Two milliliters of the conidial suspensions (about $1 \times 10^{5} \mathrm{CFU} / \mathrm{mL}$ ) were added into a $1000 \mathrm{~mL}$ conical flask containing $200 \mathrm{~mL}$ of PDB. Then all the cultivations were carried out on a rotary shaker at $140 \mathrm{rpm}$ at $28^{\circ} \mathrm{C}$. After two days of incubation, $40 \mu \mathrm{L}$ of MNQ stock solution $(10,000 \mu \mathrm{g} / \mathrm{mL})$ was added to the three bottles of cultivations as the treatment group $(2 \mu \mathrm{g} / \mathrm{mL}$ of MNQ), aseptically. The cultivations without dosing any MNQ were considered to be the control group. Then, all cultivations were carried out on a rotary shaker at $140 \mathrm{rpm}$ at $28{ }^{\circ} \mathrm{C}$ for another 2 days. For the treatment group, $2.0 \mu \mathrm{g} / \mathrm{mL}$ of MNQ was used in this work, and, without dosing, any MNQ was considered to be the control group. Three biological replicates were carried out for each condition. In this cases, sub-MIC doses of MNQ were applied to P. italicum, in order to impose stress to the cells but not induce non-specific effects associated with cell death [15]. The P. italicum mycelia were harvested after four days of cultivation. The mycelia were collected by centrifugation after being washed in three 5 -minute steps with 0.1 M PBS (pH 7.4). Part of the mycelia is used for microscopic observation and part of it is used for proteomics analysis.

\subsection{Label-Free Quantitative Proteomics}

\subsubsection{Sample Preparation}

The mycelia were obtained through centrifugation at $5000 \mathrm{~g}$ for $3 \mathrm{~min}$, and then washed with PBS buffer three times. The cell pellets were suspended on ice in $200 \mu \mathrm{L}$ of lysis buffer $(4 \%$ SDS, $100 \mathrm{mM}$ DTT, $150 \mathrm{mM}$ TrisHCl, $\mathrm{pH}$ 8.0). Cells were disrupted by a homogenizer agitated (Fastprep-24 ${ }^{\circledR}$, MP Biomedical, USA), and the lysates were boiled for $5 \mathrm{~min}$. The samples were further homogenized using ultra-sonication, and then boiled for another $5 \mathrm{~min}$. Undissolved cellular debris were removed by centrifugation at 14,000 rpm for $15 \mathrm{~min}$ and the supernatants were collected for further investigation and quantified with a BCA Protein Assay Kit (Bio-Rad, Hercules, CA, USA).

\subsubsection{Protein Digestion}

Digestion of protein (250 $\mu \mathrm{g}$ for each sample) was performed according to the FASP procedure [39]. In brief, the detergent, DTT, and low-molecular-weight constituents were removed using a $200 \mu \mathrm{L}$ UA buffer (8 M Urea, $150 \mathrm{mM}$ Tris- $\mathrm{HCl} \mathrm{pH} \mathrm{8.0)} \mathrm{by} \mathrm{repeated} \mathrm{ultra-filtration} \mathrm{(Microcon} \mathrm{units,} 30 \mathrm{kDa}$ ) facilitated by centrifugation. In order to reduce cysteine residues, $100 \mu \mathrm{L} 0.05 \mathrm{M}$ iodoacetamide added in UA buffer was to block reduced cysteine residues. These samples were incubated in the dark within $20 \mathrm{~min}$. The filter was washed with a $100 \mu \mathrm{L}$ UA buffer three times and then with a $100 \mu \mathrm{L} 25 \mathrm{mM}$ $\mathrm{NH}_{4} \mathrm{HCO}_{3}$ two times. The resulting proteins were digested using $3 \mu \mathrm{g}$ trypsin (Promega, Madison, 
WI, USA) in $40 \mu \mathrm{L} 25 \mathrm{mM} \mathrm{NH}_{4} \mathrm{HCO}_{3}$ overnight at $37^{\circ} \mathrm{C}$, and the resulting peptides were collected as a filtrate. The peptide content was estimated by a UV light spectral density of $280 \mathrm{~nm}$.

\subsubsection{Liquid Chromatography (LC)-Electrospray Ionization (ESI) Tandem MS (MS/MS) Analysis}

The peptide in each sample was desalted on C18 Cartridges (Sigma, St. Louis, MO, USA). It was then concentrated by a vacuum centrifugation and was reconstituted in $40 \mu \mathrm{L}$ of $0.1 \%(v / v)$ trifluoroacetic acid. MS experiments were performed on a $Q$ Exactive mass spectrometer coupled to an Easy nLC (ThermoFisher Scientific, Waltham, MA, USA). An aliquot comprising $5 \mu \mathrm{g}$ peptide was loaded onto a C18-reversed phase column (Thermo Scientific Easy Column, $10 \mathrm{~cm}$ long, $75 \mu \mathrm{m}$ inner diameter, $3 \mu \mathrm{m}$ resin) in buffer A ( $2 \%$ acetonitrile and $0.1 \%$ formic acid) and was separated with a linear gradient of buffer B ( $80 \%$ acetonitrile and $0.1 \%$ Formic acid) at a flow rate of $250 \mathrm{~nL} / \mathrm{min}$ controlled by an IntelliFlow technology over $120 \mathrm{~min}$. A data-dependent top 10 method dynamically choosing the most abundant precursor ions from the survey scan (300-1800 m/z) for HCD fragmentation was carried out to obtain the MS data. Determination of the target value is on the basis of the predictive Automatic Gain Control (pAGC). Each sample was carried out in MS experiments three times.

\subsubsection{Sequence Database Searching and Data Analysis}

The MS data were searched against the UniProtKB P. italicum database and were analyzed using a MaxQuant software (version 1.3.0.5). An initial search was set at a precursor mass window of $6 \mathrm{ppm}$. An enzymatic cleavage rule of Trypsin/P and a maximum of two missed cleavage sites were perform in this research. Cysteines carbamidomethylation was defined as fixed modification. Meanwhile, protein $\mathrm{N}$-terminal acetylation and methionine oxidation were defined as variable modifications. The cutoff of global FDR for peptide and protein identification was set to 0.01 . Label-free quantification was performed in MaxQuant, as preceding studies reported [40]. Protein abundance was calculated on the basis of the normalized spectral protein intensity (LFQ intensity). The fellow data of the target proteins were retrieved from the UniProtKB database in batches. Each query sequence was retrieved and loaded into Blast2GO (version 2.7.2) for GO annotation and KEGG pathway analysis.

The protein sequences of the DEPs were in batches retrieved in the FASTA format from UniProtKB database. The retrieved sequences were searched from the SwissProt database using the NCBI BLAST+ client software to find homologue sequences from which the functional annotation can be transferred to the studied sequences. The top 10 blast hits in each query sequence with E-value less than $1 \mathrm{e}^{-3}$ were retrieved and loaded into Blast2GO [41] for GO mapping and annotation. An annotation configuration with an E-value filter of $1 \mathrm{e}^{-6}$, default gradual EC weights, a GO weight of 5 , and an annotation cutoff of 75 were chosen. The unannotated sequences were then reannotated with more permissive parameters. Then, we used the looser parameters to reannotate the unannotated sequence. Lastly, the unannotated sequences and sequences without BLAST hits were then selected to go through an InterProScan [42] against EBI databases to retrieve functional annotations of protein and merge the InterProScan GO terms to the annotation set. As for the KEGG pathway analysis, the FASTA protein sequences of DEPs were blasted against the online KEGG database (http://geneontology.org/) to retrieve their KOs and were, subsequently, mapped to pathways in KEGG [43].

\subsection{Parallel Reaction Monitoring (PRM) Analysis}

In order to confirm the protein expression levels identified by label-free quantitative proteomics analysis, we further quantified the expression levels of selected proteins. Based on femtomole peptide/microgram total protein, samples were added with known amounts of each standard to determine the number of respective proteins in the sample. We used parallel reaction monitoring (PRM) to analyzed samples $[44,45]$. All fragment ions were quantified in the orbitrap after each precursor ion (light and heavy masses) was selected by the fragmented quadrupole [46]. Skyline (MacCoss Lab Software version 3.1) was used for data analysis to estimate peptide signal intensity. According to the ratio of the heavy peptide standards that were added in the known quantity, peptide concentration 
was calculated. Ion activation/dissociation was acted at a normalized collision energy of 27 in the HCD collision cell [47]. Skyline were used to analyzed the raw data where signal intensities for individual peptide sequences for each of the significantly changed proteins were quantified relative to every sample and normalized to a standard reference.

\subsection{Statistical Analysis}

Statistical analysis was performed with a one-way ANOVA in Origin 6.1 software. The statistical analysis (Student's t-test and G-test) was conducted by PepC44 on two conditions: the treatment group and the control group. The DEPs were filtered by the following cutoff: up-regulated $>2.0$-fold or down-regulated $<0.5$-fold, $p<0.05$.

\section{Conclusions}

Overall, our present investigation revealed that MNQ had a significant anti-P. italicum activity with a MIC value of $5.0 \mu \mathrm{g} / \mathrm{mL}$. The label-free protein profiling under different MNQ conditions identified a total of 3037 proteins in the control group and the treatment group. Among them, there were 129 DEPs, including 19 up-regulated proteins, 26 down-regulated proteins, and 67 proteins that were specific for the treatment group and another 17 proteins that were specific for the control group. Functional characterization by GO and KEGG enrichment results suggests that the DEPs are mainly related to energy generation, the NADPH supply, oxidative stress, and PPP. The PRM assay confirmed that the expression of the nitroreductase family protein, monooxygenase, and cytochrome $\mathrm{P} 450$ are significantly down-regulated in the P. italicum with MNQ treatment. Based on the microscopic observation and the proteomics results mentioned above, we speculated that the proteins associated with energy production, NADPH supply, and other functions in P. italicum were altered to reduce the damage caused by MNQ. Thus, these findings will contribute to further understanding of the possible new molecular action of MNQ against $P$. italicum.

Supplementary Materials: Supplementary materials can be found at http://www.mdpi.com/1422-0067/20/14/ $3459 / \mathrm{s} 1$. Table S1. The proteins identified in the treatment group and the control group. Figure S1. Effects of MNQ against P. italicum in different concentrations. Figure S2. Top 10 pathway enrichments of the identified DEPs.

Author Contributions: Conceptualization, R.-M.H. and L.-M.H.; methodology, M.G.; X.Z.; R.H.; L.H. and M.L. validation, M.G. and X.D.; formal analysis, D.Z.; investigation, M.G.; X.Z.; T.L. and X.D.; data curation, M.L. and T.L.; writing—original draft preparation, X.Z.; writing-review and editing, M.G.; and funding acquisition, R.H. and L.H.

Funding: The Science and Technology Planning Project of Guangdong Province, Guangzhou Planned Program in Science and Technology, Program of Department of Ocean and Fisheries of Guangdong Province, Natural Science Foundation of Guangdong, Guangdong Provincial Key Laboratory of Applied Botany, South China Botanical Garden, Chinese Academy of Sciences, Finance Special Project of Zhanjiang City, Natural Science Foundation of Guangdong, grant number 2017A020217002, 201803020003, GDME2018C014, 2016A030313151, AB2018004, 2018A01044, and 2018A0303070018, funded this research.

Conflicts of Interest: The authors declare no conflict of interest.

$\begin{array}{ll}\text { Abbreviations } \\ \text { MNQ } & \text { 2-Methoxy-1,4-naphthoquinone } \\ \text { MIC } & \text { Minimum inhibitory concentration } \\ \text { PRM } & \text { Parallel reaction monitoring } \\ \text { FDR } & \text { False discovery rate } \\ \text { DEPs } & \text { Differentially expressed proteins } \\ \text { GO } & \text { Gene ontology } \\ \text { KEGG } & \text { Kyoto encyclopedia of genes and genomes } \\ \text { BP } & \text { Biological process } \\ \text { CC } & \text { Cellular component } \\ \text { MF } & \text { Molecular function } \\ \text { ACAD } & \text { Acyl-CoA dehydrogenase }\end{array}$




$\begin{array}{ll}\text { ME } & \text { Malic enzyme } \\ \text { 6PGDH } & \text { 6-Phosphogluconate dehydrogenase } \\ \text { ROS } & \text { Reactive oxygen species } \\ \text { CAT } & \text { Catalase } \\ \text { GS } & \text { Glutathione synthetase } \\ \text { PPP } & \text { Pentose phosphate pathway } \\ \text { RPE } & \text { Ribulose-phosphate 3-epimerase } \\ \text { KOs } & \text { Protein number at KEGG database } \\ \text { PDA } & \text { Potato dextrose agar } \\ \text { PDB } & \text { Potato dextrose broth } \\ \text { HCD } & \text { Higher energy dissociation } \\ \text { pAGC } & \text { Predictive automatic gain control } \\ \text { DMSO } & \text { Dimethylsulfoxide } \\ \text { PBS } & \text { Phosphate buffered saline }\end{array}$

\section{References}

1. Rabea, E.I.; Badawy, M.E.I.; Steurbaut, W.; Stevens, C.V. In vitro assessment of N-(benzyl)chitosan derivatives against some plant pathogenic bacteria and fungi. Eur. Polym. J. 2009, 45, 237-245. [CrossRef]

2. Gao, Y.Y.; He, L.F.; Li, X.X.; Lin, J.; Mu, W.; Liu, F. Toxicity and biochemical action of the antibiotic fungicide tetramycin on Colletotrichum scovillei. Pestic. Biochem. Phys. 2018, 147, 51-58. [CrossRef] [PubMed]

3. Chen, C.Y.; Qi, W.W.; Peng, X.; Chen, J.Y.; Wan, C.P. Inhibitory effect of 7-demethoxytylophorine on Penicillium italicum and its possible mechanism. Microorganisms 2019, 7, 36. [CrossRef] [PubMed]

4. Talibi, I.; Boubaker, H.; Boudyach, E.H.; Ben Aoumar, A.A. Alternative methods for the control of postharvest citrus diseases. J. Appl. Microbiol. 2014, 117, 1-17. [CrossRef] [PubMed]

5. Wan, C.P.; Li, P.; Chen, C.Y.; Peng, X.; Li, M.X.; Chen, M.; Wang, J.S.; Chen, J.Y. Antifungal activity of Ramulus cinnamomi explored by 1H-NMR based metabolomics approach. Molecules 2017, 22, 2237. [CrossRef] [PubMed]

6. Tao, N.G.; Jia, L.; Zhou, H.E.; He, X.L. Effect of octanal on the mycelial growth of Penicillium italicum and P-digitatum. World J. Microb. Biot. 2014, 30, 1169-1175. [CrossRef]

7. Tao, N.G.; OuYang, Q.L.; Jia, L. Citral inhibits mycelial growth of Penicillium italicum by a membrane damage mechanism. Food Control 2014, 41, 116-121. [CrossRef]

8. Yang, S.Z.; Zhou, J.; Li, D.M.; Shang, C.Y.; Peng, L.T.; Pan, S.Y. The structure-antifungal activity relationship of 5,7-dihydroxyflavonoids against Penicillium italicum. Food Chem. 2017, 224, 26-31. [CrossRef]

9. Jiang, H.F.; Zhuang, Z.H.; Hou, B.W.; Shi, B.J.; Shu, C.J.; Chen, L.; Shi, G.X.; Zhang, W.M. Adverse effects of hydroalcoholic extracts and the major components in the stems of Impatiens balsamina L. on Caenorhabditis elegans. Evid. Based Complement. Altern. Med. 2017, 2017, 4245830. [CrossRef]

10. Wang, Y.C.; Lin, Y.H. Anti-gastric adenocarcinoma activity of 2-methoxy-1,4-naphthoquinone, an anti-Helicobacter pylori compound from Impatiens balsamina L. Fitoterapia 2012, 83, 1336-1344. [CrossRef]

11. Liew, K.; Yong, P.V.C.; Navaratnam, V.; Lim, Y.M.; Ho, A.S.H. Differential proteomic analysis on the effects of 2-methoxy-1,4-naphthoquinone towards MDA-MB-231 cell line. Phytomedicine 2015, 22, 517-527. [CrossRef] [PubMed]

12. Colwell, C.A.; Mccall, M. Studies on the mechanism of antibacterial action of 2-methyl-1,4-naphthoquinone. Science 1945, 101, 592-594. [CrossRef] [PubMed]

13. Ding, Z.S.; Jiang, F.S.; Chen, N.P.; Lv, G.Y.; Zhu, C.G. Isolation and identification of an anti-tumor component from leaves of Impatiens balsamina. Molecules 2008, 13, 220-229. [CrossRef] [PubMed]

14. Guo, S.C.; Zou, J.; Wang, G.D. Advances in the proteomic discovery of novel therapeutic targets in cancer. Drug Des. Dev. Ther. 2013, 7, 1259-1271. [CrossRef] [PubMed]

15. Liu, X.F.; Pai, P.J.; Zhang, W.P.; Hu, Y.W.; Dong, X.J.; Qian, P.Y.; Chen, D.J.; Lam, H. Proteomic response of methicillin-resistant $S$. aureus to a synergistic antibacterial drug combination: A novel erythromycin derivative and oxacillin. Sci. Rep. 2016, 6, 19841. [CrossRef] [PubMed]

16. Ashburner, M.; Ball, C.A.; Blake, J.A.; Botstein, D.; Butler, H.; Cherry, J.M.; Davis, A.P.; Dolinski, K.; Dwight, S.S.; Eppig, J.T.; et al. Gene ontology: Tool for the unification of biology. Nat. Genet. 2000, 25, 25-29. [CrossRef] [PubMed] 
17. Du, C.; Liu, H.F.; Lin, Y.Z.; Wang, X.F.; Ma, J.; Li, Y.J.; Wang, X.J.; Zhou, J.H. Proteomic alteration of equine monocyte-derived macrophages infected with equine infectious anemia virus. Proteomics 2015, 15, 1843-1858. [CrossRef]

18. Wenzel, M.; Bandow, J.E. Proteomic signatures in antibiotic research. Proteomics 2011, 11, 3256-3268. [CrossRef]

19. Burchmore, R. Mapping pathways to drug resistance with proteomics. Expert Rev. Proteom. 2014, 11, 1-3. [CrossRef]

20. Parveen, M.; Hasan, M.K.; Takahashi, J.; Murata, Y.; Kitagawa, E.; Kodama, O.; Iwahashi, H. Response of Saccharomyces cerevisiae to a monoterpene: Evaluation of antifungal potential by DNA microarray analysis. J. Antimicrob. Chemoth. 2004, 54, 46-55. [CrossRef]

21. Han, Q. Control Effect and mechanism of triazole fungicides folicur and caramba on Fusarium head blight and wheat Stripe Rust. Northwest Sci-Tech Univ. Agric. For. 2003, 96, 1712-1728.

22. Cai, T.T.; Hua, B.X.; Luo, D.W.; Xu, L.R.; Cheng, Q.Y.; Yuan, G.S.; Yan, Z.Q.; Sun, N.; Hua, L.C.; Lu, C. The circadian protein CLOCK regulates cell metabolism via the mitochondrial carrier SLC25A10. Biochim. Biophys. Acta Mol. Cell Res. 2019, 1866, 1310-1321. [CrossRef] [PubMed]

23. Anwar, A.; She, M.Y.; Wang, K.; Riaz, B.; Ye, X.G. Biological roles of ornithine aminotransferase (OAT) in plant stress tolerance: Present progress and future perspectives. Int. J. Mol. Sci. 2018, 19, 3681. [CrossRef] [PubMed]

24. Swigonova, Z.; Mohsen, A.W.; Vockley, J. Acyl-CoA dehydrogenases: Dynamic history of protein family evolution. J. Mol. Evol. 2009, 69, 176-193. [CrossRef] [PubMed]

25. Camoes, F.; Islinger, M.; Guimaraes, S.C.; Kilaru, S.; Schuster, M.; Godinho, L.F.; Steinberg, G.; Schrader, M. New insights into the peroxisomal protein inventory: Acyl-CoA oxidases and -dehydrogenases are an ancient feature of peroxisomes. Biochim. Biophys. Acta Mol. Cell Res. 2015, 1853, 111-125. [CrossRef]

26. Rodriguez, E.; Romaris, F.; Lorenzo, S.; Moreno, J.; Bonay, P.; Ubeira, F.M.; Garate, T. A recombinant enolase from Anisakis simplex is differentially recognized in natural human and mouse experimental infections. Med. Microbiol. Immun. 2006, 195, 1-10. [CrossRef] [PubMed]

27. Ye, C.X.; Wan, F.; Sun, Z.Z.; Cheng, C.H.; Ling, R.Z.; Fan, L.F.; Wang, A.L. Effect of phosphorus supplementation on cell viability, anti-oxidative capacity and comparative proteomic profiles of puffer fish (Takifugu obscurus) under low temperature stress. Aquaculture 2016, 452, 200-208. [CrossRef]

28. Ito, S.; Osanai, T. Single amino acid change in 6-phosphogluconate dehydrogenase from Synechocystis conveys higher affinity for NADP(+) and altered mode of inhibition by NADPH. Plant Cell Physiol. 2018, 59, 2452-2461. [CrossRef]

29. Khan, A.R.; Ullah, I.; Waqas, M.; Shahzad, R.; Hong, S.J.; Park, G.S.; Jung, B.K.; Lee, I.J.; Shin, J.H. Plant growth-promoting potential of endophytic fungi isolated from Solanum nigrum leaves. World J. Microb. Biot. 2015, 31, 1461-1466. [CrossRef]

30. Delgado, J.; Owens, R.A.; Doyle, S.; Asensio, M.A.; Nunez, F. Impact of the antifungal protein PgAFP from Penicillium chrysogenum on the protein profile in Aspergillus flavus. Appl. Microbiol. Biot. 2015, 99, 8701-8715. [CrossRef]

31. Lopez-Moya, F.; Suarez-Fernandez, M.; Lopez-Llorca, L.V. Molecular mechanisms of chitosan interactions with fungi and plants. Int. J. Mol. Sci. 2019, 20, 332. [CrossRef] [PubMed]

32. Pompella, A.; Visvikis, A.; Paolicchi, A.; De Tata, V.; Casini, A.F. The changing faces of glutathione, a cellular protagonist. Biochem. Pharmacol. 2003, 66, 1499-1503. [CrossRef]

33. Khullar, S.; Reddy, M.S. Cadmium and arsenic responses in the ectomycorrhizal fungus Laccaria bicolor: Glutathione metabolism and its role in metal(loid) homeostasis. Environ. Microbiol. Rep. 2019, 11, 53-61. [CrossRef] [PubMed]

34. Lykins, J.D.; Filippova, E.V.; Halavaty, A.S.; Minasov, G.; Zhou, Y.; Dubrovska, I.; Flores, K.J.; Shuvalova, L.A.; Ruan, J.P.; El Bissati, K.; et al. CSGID solves structures and identifies phenotypes for five enzymes in Toxoplasma gondii. Front Cell Infect. Microbiol. 2018, 8, 352. [CrossRef] [PubMed]

35. Shimaoka, M.; Kawasaki, H.; Takenaka, Y.; Kurahashi, O.; Matsui, H. Effects of edd and pgi disruptions on inosine accumulation in Escherichia coli. Biosci. Biotechnol. Biochem. 2005, 69, 1248-1255. [CrossRef] [PubMed]

36. Myresiotis, C.K.; Karaoglanidis, G.S.; Tzavella-Monari, K. Resistance of Botrytis cinerea isolates from vegetable crops to anilinopyrimidine, phenylpyrrole, hydroxyanilide, benzimidazole, and dicarboximide fungicides. Plant Dis. 2007, 91, 407-413. [CrossRef] [PubMed] 
37. Agarwal, M.; Walia, S.; Dhingra, S.; Khambay, B.P. Insect growth inhibition, antifeedant and antifungal activity of compounds isolated/derived from Zingiber offcinale Roscoe (ginger) rhizomes. Pest Manag. Sci. 2001, 57, 289-300. [CrossRef]

38. Xing, C.; Qin, C.Q.; Li, X.Q.; Zhang, F.M.; Linhardt, R.J.; Sun, P.L.; Zhang, A.Q. Chemical composition and biological activities of essential oil isolated by HS-SPME and UAHD from fruits of bergamot. LWT Food Sci. Technol. 2019, 104, 38-44. [CrossRef]

39. Wisniewski, J.R.; Zougman, A.; Nagaraj, N.; Mann, M. Universal sample preparation method for proteome analysis. Nat. Methods 2009, 6, 359-360. [CrossRef]

40. Luber, C.A.; Cox, J.; Lauterbach, H.; Fancke, B.; Selbach, M.; Tschopp, J.; Akira, S.; Wiegand, M.; Hochrein, H.; O'Keeffe, M.; et al. Quantitative proteomics reveals subset-specific viral recognition in dendritic cells. Immunity 2010, 32, 279-289. [CrossRef]

41. Gotz, S.; Garcia-Gomez, J.M.; Terol, J.; Williams, T.D.; Nagaraj, S.H.; Nueda, M.J.; Robles, M.; Talon, M.; Dopazo, J.; Conesa, A. High-throughput functional annotation and data mining with the Blast2GO suite. Nucleic Acids Res. 2008, 36, 3420-3435. [CrossRef] [PubMed]

42. Quevillon, E.; Silventoinen, V.; Pillai, S.; Harte, N.; Mulder, N.; Apweiler, R.; Lopez, R. InterProScan: Protein domains identifier. Nucleic Acids Res. 2005, 33, 116-120. [CrossRef] [PubMed]

43. Kanehisa, M.; Goto, S.; Sato, Y.; Furumichi, M.; Tanabe, M. KEGG for integration and interpretation of large-scale molecular data sets. Nucleic Acids Res. 2012, 40, 109-114. [CrossRef] [PubMed]

44. Saito, M.A.; Bertrand, E.M.; Dutkiewicz, S.; Bulygin, V.V.; Moran, D.M.; Monteiro, F.M.; Follows, M.J.; Valois, F.W.; Waterbury, J.B. Iron conservation by reduction of metalloenzyme inventories in the marine diazotroph Crocosphaera watsonii. Proc. Natl. Acad. Sci. USA 2011, 108, 2184-2189. [CrossRef] [PubMed]

45. Lange, V.; Malmstrom, J.A.; Didion, J.; King, N.L.; Johansson, B.P.; Schafer, J.; Rameseder, J.; Wong, C.H.; Deutsch, E.W.; Brusniak, M.Y.; et al. Targeted quantitative analysis of Streptococcus pyogenes virulence factors by multiple reaction monitoring. Mol. Cell. Proteom. 2008, 7, 1489-1500. [CrossRef] [PubMed]

46. Gallien, S.; Duriez, E.; Crone, C.; Kellmann, M.; Moehring, T.; Domon, B. Targeted proteomic quantification on quadrupole-orbitrap mass spectrometer. Mol. Cell. Proteom. 2012, 11, 1709-1723. [CrossRef] [PubMed]

47. MacLean, B.; Tomazela, D.M.; Shulman, N.; Chambers, M.; Finney, G.L.; Frewen, B.; Kern, R.; Tabb, D.L.; Liebler, D.C.; MacCoss, M.J. Skyline: An open source document editor for creating and analyzing targeted proteomics experiments. Bioinformatics 2010, 26, 966-968. [CrossRef] 